\title{
Interaction between the basolateral amygdala and dorsal hippocampus is critical for cocaine memory reconsolidation and subsequent drug context-induced cocaine-seeking behavior in rats
}

\author{
Audrey M. Wells, Heather C. Lasseter, Xiaohu Xie, Kate E. Cowhey, Andrew M. Reittinger, \\ and Rita A. Fuchs ${ }^{1}$ \\ Department of Psychology, University of North Carolina, Chapel Hill, North Carolina 27599-3270, USA
}

\begin{abstract}
Contextual stimulus control over instrumental drug-seeking behavior relies on the reconsolidation of context-responsedrug associative memories into long-term memory storage following retrieval-induced destabilization. According to previous studies, the basolateral amygdala (BLA) and dorsal hippocampus (DH) regulate cocaine-related memory reconsolidation; however, it is not known whether these brain regions interact or independently control this phenomenon. To investigate this question, rats were trained to lever press for cocaine reinforcement in a distinct environmental context followed by extinction training in a different context. Rats were then briefly re-exposed to the cocaine-paired context to destabilize cocaine-related memories, or they were exposed to an unpaired context. Immediately thereafter, the rats received unilateral microinfusions of anisomycin (ANI) into the BLA plus baclofen/muscimol (B/M) into the contralateral (BLA/ $\mathrm{DH}$ disconnection) or ipsilateral $\mathrm{DH}$, or they received contralateral or ipsilateral microinfusions of vehicle. They then remained in their home cages overnight or for $2 \mathrm{l}$, followed by additional extinction training and a test of cocaineseeking behavior (nonreinforced active lever responding). BLA/DH disconnection following re-exposure to the cocainepaired context, but not the unpaired context, impaired subsequent drug context-induced cocaine-seeking behavior relative to vehicle or ipsilateral ANI $+\mathrm{B} / \mathrm{M}$ treatment. Prolonged home cage stay elicited a time-dependent increase, or incubation, of drug-context-induced cocaine-seeking behavior, and BLA/DH disconnection inhibited this incubation effect despite some recovery of cocaine-seeking behavior. Thus, the BLA and DH interact to regulate the reconsolidation of cocaine-related associative memories, thereby facilitating the ability of drug-paired contexts to trigger cocaine-seeking behavior and contributing to the incubation of cocaine-seeking behavior.
\end{abstract}

[Supplemental material is available for this article.]

Exposure to cocaine-associated environments can elicit craving and promote relapse in former addicts (Childress et al. 1988; O’Brien et al. 1992; Foltin and Haney 2000). Similarly, re-exposure to a previously cocaine-paired context reinstates extinguished cocaine-seeking behavior in rats, and this phenomenon depends on robust context-response-cocaine associations (Alleweireldt et al. 2001; Fuchs et al. 2005; Kearns and Weiss 2007; Crombag et al. 2008). According to the memory reconsolidation hypothesis, the memories of previously learned associations are rendered labile during retrieval and must be restabilized, or "reconsolidated," into long-term memory storage in order to exert persistent stimulus control over conditioned behaviors (Misanin et al. 1968; Lewis 1979; Nader et al. 2000a; Tronson and Taylor 2007), including drug-seeking behavior (Lee et al. 2005; Miller and Marshall 2005; Bernardi et al. 2006, 2009; Milekic et al. 2006; Valjent et al. 2006; Diergaarde et al. 2008). Hence, a greater understanding of the neural circuitry and mechanisms underlying cocainerelated memory reconsolidation may inform the development of novel treatments for drug addiction (Taylor et al. 2009; Milton and Everitt 2010).

\footnotetext{
${ }^{1}$ Corresponding author.
}

E-mail rfuchs@email.unc.edu.

Article is online at http://www.learnmem.org/cgi/doi/10.1101//m.2273111.
The basolateral amygdala (BLA) is integral to the expression of both cue- and context-induced reinstatement of cocaine seeking (Meil and See 1997; Fuchs et al. 2002, 2005, 2007; Kantak et al. 2002) and is a site for memory reconsolidation (Nader et al. 2000a; Milekic et al. 2007; Mamiya et al. 2009; Li et al. 2010). The BLA is critically involved in the reconsolidation of conditioned stimulus (CS)-drug associative memories that regulate drug-conditioned place preference (Milekic et al. 2006; Li et al. 2010; Théberge et al. 2010), conditioned reinforcement, and drug-seeking behavior (Lee et al. 2005, 2006; Milton et al. 2008; Théberge et al. 2010). Furthermore, research from our laboratory has demonstrated that anisomycin (ANI)-sensitive processes (i.e., protein synthesis and/or post-translational modification) (for review, see Gold 2008) in the BLA control the reconsolidation of context-response-cocaine associative memories and the subsequent ability of a drug-paired context to reinstate extinguished cocaine-seeking behavior (Fuchs et al. 2009).

Similar to the BLA, the dorsal hippocampus (DH) is required for the expression of drug context-induced cocaine-seeking behavior in rats (Fuchs et al. 2005, 2007), but its exact contribution to the reconsolidation of cocaine-related associative memories remains unclear. Tetrodotoxin-induced neuronal inactivation of, but not ANI treatment in, the DH following re-exposure to a cocaine-paired context inhibits subsequent 
drug context-induced reinstatement of cocaine-seeking behavior (Ramirez et al. 2009). This effect is cocaine memory reactivationdependent, indicating that, while the $\mathrm{DH}$ is not a critical site for protein synthesis and/or post-translational modification required for memory re-stabilization, per se, it is necessary for the utilization of memories that have been reconsolidated elsewhere, perhaps in the BLA.

Intrahemispheric interaction between the BLA and DH is required for the expression of drug context-induced cocaineseeking behavior (Fuchs et al. 2007). Thus, interactions between these brain regions may also be necessary for memory reconsolidation, including the stabilization of cocaine-related associative memories that regulate cocaine-seeking behavior. In support of this idea, neuronal populations within subregions of the BLA and DH exhibit synchronized neural activity concomitant with the reconsolidation of remote fear memories (Narayanan et al. 2007). However, to date, it has not been investigated whether the BLA and DH interact or independently regulate memory reconsolidation. Hence, Experiment 1 in the present study employed a disconnection manipulation to test the hypothesis that intrahemispheric interaction between the BLA and $\mathrm{DH}$ at the time of memory reconsolidation is necessary for the ability of a cocaine-paired context to subsequently elicit cocaine-seeking behavior. Additional experiments examined whether the effects of BLA/DH functional disconnection at the time of memory restabilization were memory reactivation-dependent (Experiment 2) and whether BLA/DH functional disconnection produced prolonged impairment in drug context-induced cocaineseeking behavior (Experiment 3), as is expected following genuine memory reconsolidation impairment (Alberini et al. 2006; Nader and Wang 2006).

\section{Results}

\section{Histology}

Schematics and photomicrographs representing cannula placements are included in Figure 1. The target brain regions were defined as the lateral and basolateral nuclei of the amygdala and the dorsal hippocampus proper. Further inspection of neural tissue using high power microscopy revealed no indication of tissue damage (i.e., extensive cell loss or gliosis). Data from rats with misplaced cannulae were excluded from subsequent statistical analyses. The resulting $n$ 's per vehicle (VEH)- and drug-treated groups were: contralateral VEH (BLA) + VEH (DH) $0 \mathrm{~d}$, $n=8$; contralateral VEH $(\mathrm{BLA})+\mathrm{VEH}$ (DH) $21 \mathrm{~d}, n=7$; contralateral ANI (BLA) $+\mathrm{B} / \mathrm{M}(\mathrm{DH}) 0 \mathrm{~d}, n=10$; contralateral ANI (BLA) + B/M (DH) $21 \mathrm{~d}, n=7$; ipsilateral VEH (BLA) + VEH (DH), $n=8$; ipsilateral ANI (BLA) + B/M (DH), $n=7$; Paxinos and Watson (1997). no reactivation contralateral VEH (BLA) $+\mathrm{VEH}(\mathrm{DH}), n=7$; and no reactivation contralateral ANI (BLA) $+\mathrm{B} / \mathrm{M}(\mathrm{DH}), n=7$.

\section{Behavioral history}

Analysis of variance (ANOVA) did not indicate any pre-existing differences between the groups in cocaine intake, in active or inactive lever responding during cocaine self-administration training, extinction training, during the memory reactivation session, or in the number of days required to reach the extinction criterion before testing. These data are provided in Supplementary Table S1. Correlational analyses revealed that active lever responding during the memory reactivation session did not significantly predict active lever responding during the test of drug
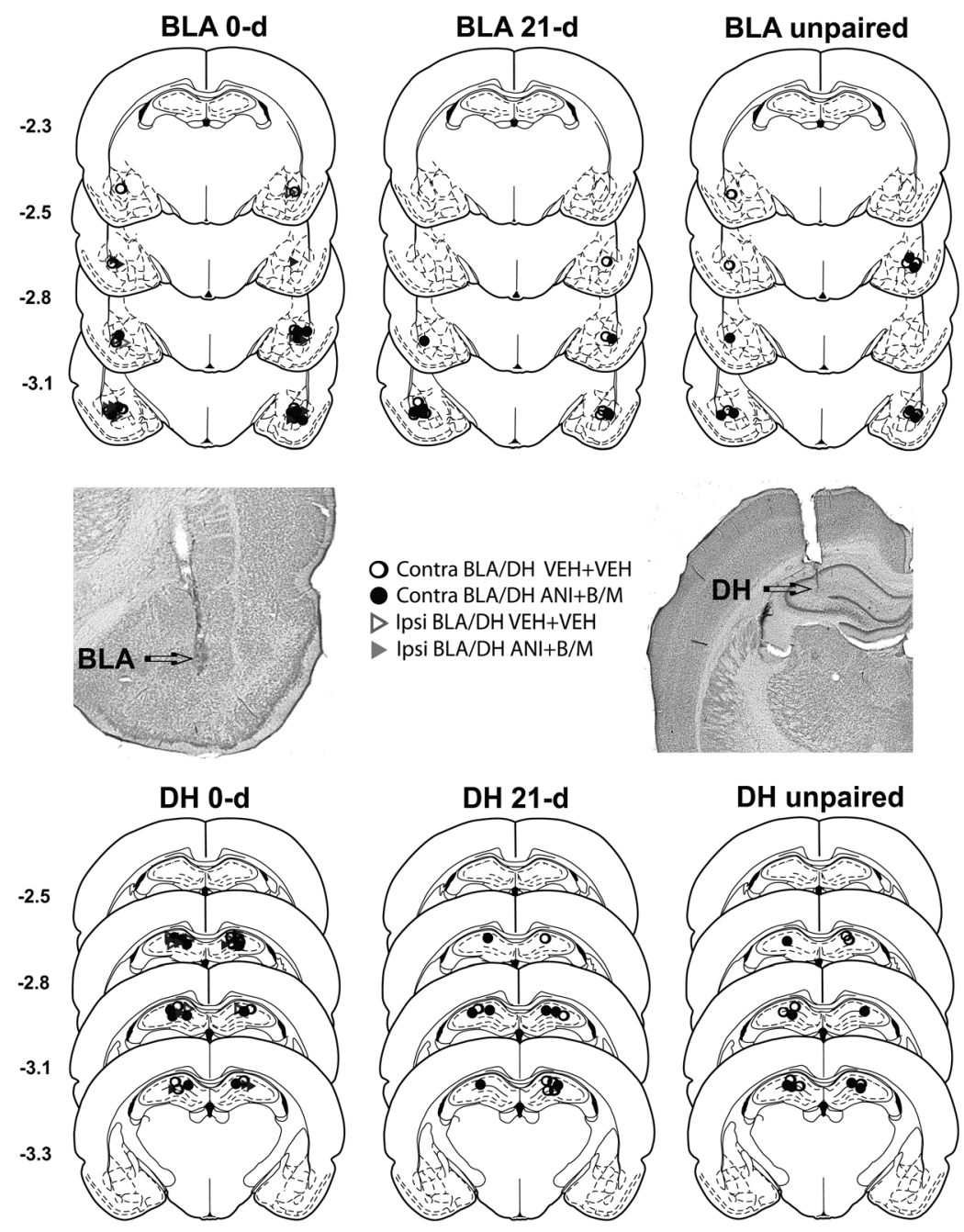

Figure 1. Schematics and photomicrographs depicting cannula placement. Arrows mark the most ventral point of injector cannula tracts for cannulae aimed at the BLA and DH on photomicrographs of representative cresyl violet-stained sections. The symbols on the schematics denote the most ventral point of the injector cannula tracts for rats that received unilateral microinfusions of vehicle into the BLA plus VEH into the contralateral DH (open circles), anisomycin (ANI) into the BLA plus baclofen/muscimol (B/M) into the contralateral DH (filled-in, black circles), VEH into the BLA plus VEH into the ipsilateral DH (open triangles), or ANI into the BLA plus B/M into the ipsilateral DH (filled-in, gray triangles). The groups were assigned to remain in their home cages overnight (i.e., $0 \mathrm{~d}$ ) or for $21 \mathrm{~d}$ following the intracranial manipulations. Additionally, control groups received microinfusions following exposure to an unpaired context and remained in their home cages overnight following the intracranial manipulations. Numbers indicate the distance from bregma in $\mathrm{mm}$, according to the rat brain atlas of 
context-induced cocaine seeking for the groups that had received VEH $(r=0.114, P=0.604)$ or ANI $+\mathrm{B} / \mathrm{M}$ treatment following the memory reactivation session $(r=0.496, P=0.495)$. Furthermore, none of the analyses revealed hemisphere-dependent effects (i.e., laterality, data not shown). Only statistically significant effects are reported below. The eta-squared estimates of effect size for all statistically significant effects ranged between 0.015 and 0.770 .

\section{Experiment 1}

Experiment 1 was designed to evaluate whether intrahemispheric interaction between the BLA and DH is necessary for cocainerelated memory reconsolidation and for the subsequent ability of a cocaine-paired context to reinstate cocaine-seeking behavior (see experimental timeline in Fig. 2A). This was achieved by examining the effects of functional disconnection of the BLA and DH following cocaine memory reactivation (i.e., re-exposure to the previously cocaine-paired context) on drug context-induced cocaine-seeking behavior. Rats received unilateral infusions of ANI into the BLA plus B/M into the contralateral DH (disconnection) or ipsilateral DH (ipsilateral control). Additional control groups received ipsilateral or contralateral infusions of VEH into the BLA and DH. The contralateral ANI $+\mathrm{B} / \mathrm{M}$ manipulation was expected to bilaterally disrupt putative intrahemispheric interactions between the BLA and DH. Conversely, the ipsilateral manipulation was expected to bilaterally disrupt interhemispheric connections between the BLA and DH while sparing intrahemispheric interactions between these brain regions in the unmanipulated hemisphere (Olton et al. 1982; Gaffan et al. 1993). Thus, it was postulated that requisite intrahemispheric interactions between the BLA and $\mathrm{DH}$ would be indicated by greater deficit in cocaine seeking following the contralateral manipulation relative to the ipsilateral manipulation.

BLA/DH disconnection following cocaine memory reactivation attenuated subsequent cocaine-seeking behavior in a contextand lever-dependent manner, while the ipsilateral $\mathrm{ANI}+\mathrm{B} / \mathrm{M}$ manipulation had no effect on responding relative to $\mathrm{VEH}$ (see Fig. $2 \mathrm{~B}$ ). The $2 \times 2 \times 2$ ANOVA of active lever responses indicated a significant surgery type $\times$ treatment $\times$ context interaction effect $\left(F_{(1,29)}=4.679, P=0.039\right)$, as well as significant surgery type $\times$ context interaction $\left(F_{(1,29)}=8.473, P=0.007\right)$, treatment $\times$ surgery type interaction $\left(F_{(1,29)}=5.209, P=0.030\right)$, context main $\left(F_{(1,29)}=66.482, P<0.001\right)$, and surgery type main $\left(F_{(1,29)}=\right.$ $8.463, P=0.007)$ effects. Thus, re-exposure to the cocaine-paired context during testing elicited an increase in active lever responding in both VEH control groups and in the ipsilateral ANI + B/ $\mathrm{M}$-treated control group, relative to responding in the extinction context (ANOVA context simple main effect, Tukey test, $P<$ $0.05)$. Conversely, the group that had received BLA/DH disconnection manipulation (i.e., contralateral ANI + B/M treatment) following cocaine memory reactivation subsequently exhibited less active lever responding in the cocaine-paired, but not the extinction context, relative to all other groups (ANOVA treatment and surgery type simple main effects, Tukey test, $P<0.05$ ). As a result, responding in this group was not different in the cocaine-paired and extinction contexts on the test days.

Time course analysis of active lever responding revealed that the effects of contralateral $\mathrm{ANI}+\mathrm{B} / \mathrm{M}$ treatment on drug context-induced cocaine-seeking behavior were independent of time interval (see Fig. 2D). The $2 \times 2 \times 6$ ANOVA of active lever responses across the six 20-min intervals of the test session revealed a significant surgery type $\times$ treatment interaction effect $\left(F_{(1,29)}=\right.$ 5.196, $P=0.030)$, as well as time main $\left(F_{(5,145)}=10.978, P<\right.$ $0.001)$ and surgery type main $\left(F_{(1,29)}=8.45, P=0.007\right)$ effects. Active lever responding decreased during the test session (ANOVA time main effect, interval $1>$ intervals 2-6, Tukey test,
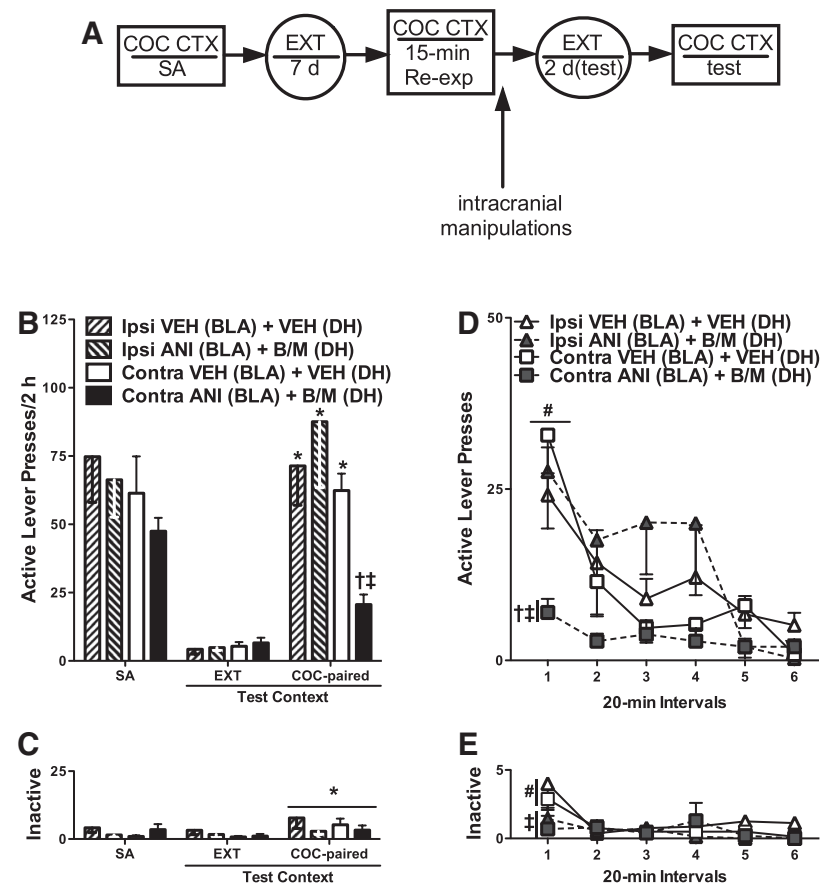

Figure 2. BLA/DH disconnection following cocaine memory reactivation attenuates subsequent drug context-induced cocaine-seeking behavior relative to $\mathrm{VEH}$ or ipsilateral $\mathrm{ANI}+\mathrm{B} / \mathrm{M}$ treatment. $(A)$ Schematic depicting the timeline for Experiment 1. Cocaine self-administration sessions (SA) were conducted in a distinct context followed by extinction (EXT) training in a different context. On post-cocaine day 8 , rats were re-exposed to the cocaine-paired context (COC-CTX) for 15 min to reactivate cocaine-related memories and then received unilateral microinfusions of anisomycin (ANI, $62.5 \mu \mathrm{g} / 0.5 \mu \mathrm{L}$ ) into the BLA plus baclofen/ muscimol $(B / M, 1.0 / 0.01 \mathrm{mM} / 0.5 \mu \mathrm{L})$ into the contralateral or ipsilateral $\mathrm{DH}$. Control rats received microinfusions of phosphate buffered saline vehicle (VEH, $0.5 \mu \mathrm{L}$ ) into the corresponding brain regions. Groups then remained in their home cages overnight, followed by additional extinction training until they reached the extinction criterion ( $\leq 25$ active lever responses/session on two consecutive days) and a test of drug context-induced cocaine seeking. ( $B$ ) Mean ( \pm SEM) active lever presses during self-administration (SA; mean of the last three training sessions) and during tests of cocaine-seeking behavior in the extinction context (EXT; the last session preceding the test in the cocaine-paired context) and in the cocaine-paired context (COC-paired). (C) Mean ( \pm SEM) inactive lever presses. $(D)$ The time course of active lever responses (mean \pm SEM) during the test in the cocaine-paired context. $(E)$ The time course of inactive lever responses (mean \pm SEM). $\left({ }^{*}\right)$ Significant difference relative to responding in the extinction context (ANOVA context simple main effect, $P<0.05)$. ( $\dagger$ ) Significant difference relative to ipsilateral $\mathrm{ANI}+\mathrm{B} / \mathrm{M}$ treatment (ANOVA surgery-type simple main effect, $P<$ 0.05). ( $\$$ ) Significant difference relative to VEH treatment (ANOVA treatment simple main effect, $P<0.05$ ). (\#) Significant difference relative to all other time intervals (ANOVA time simple main effects, $P<0.05$ ).

$P<0.05)$. Collapsed across time interval, there was no difference in active lever responding between the VEH control groups and the ipsilateral ANI $+\mathrm{B} / \mathrm{M}$-treated group. In contrast, the group that had received BLA/DH disconnection manipulation following cocaine memory reactivation subsequently exhibited less active lever responding relative to all other groups (ANOVA treatment and surgery type simple main effects, Tukey test, $P<0.05$ ).

The $2 \times 2 \times 2$ ANOVA for inactive lever responses indicated that exposure to the cocaine-paired context elicited a slight increase in inactive lever responding in all groups relative to responding in the extinction context (ANOVA context main effect only, $F_{(1,29)}=6.599, P=0.016$ ) (see Fig. $2 \mathrm{C}$ ). Time course analysis of inactive lever responses during the test of drug context-induced 
cocaine seeking revealed a significant treatment $\times$ time interaction effect $\left(F_{(5,145)}=2.446, P=0.037\right)$ and a time main effect $\left(F_{(5,145)}=5.625, P<0.001\right)$. Independent of surgery-type, $\mathrm{VEH}$ groups exhibited a decrease in inactive lever responding during the test session (ANOVA time simple main effects, interval $1>$ intervals $2-6$, Tukey test, $P<0.05$ ). Furthermore, the groups that had received ipsilateral or contralateral $\mathrm{ANI}+\mathrm{B} / \mathrm{M}$ treatment following memory reactivation exhibited less inactive lever responding than VEH groups during interval 1 (ANOVA treatment simple main effect, Tukey test, $P<0.05$ ).

\section{Motor activity}

The protracted effects of intracranial manipulations on general activity can impact instrumental cocaine-seeking behavior. To examine this possibility, general motor activity was evaluated by measuring photobeam breaks during a 2 -h session in a novel Plexiglas chamber $(42 \times 20 \times 20 \mathrm{~cm})$ that was equipped with an array of eight photodetectors. The test occurred $24 \mathrm{~h}$ after the test of drug context-induced cocaine seeking.

General motor activity gradually declined as rats habituated to the chamber, and this effect was independent of treatment. These data are provided in Supplementary Figure S1. The $2 \times$ $2 \times 6$ ANOVA of photobeam breaks revealed a significant time main effect only $\left(F_{(5,145)}=104.272, P<0.001\right)$. Collapsed across surgery type and treatment, rats generated fewer photobeam breaks during intervals $2-6$ relative to the first 20-min interval of the session (Tukey test, $P<0.05$ ). Importantly, neither BLA/ DH disconnection nor the ipsilateral manipulation with ANI + $\mathrm{B} / \mathrm{M}$ administered following memory reactivation altered subsequent general motor activity relative to VEH treatment.

\section{Experiment 2}

Memory reconsolidation deficits are expected to depend on memory reactivation (Nader et al. 2000b; Alberini et al. 2006; Tronson and Taylor 2007). Thus, we evaluated whether the effects of BLA/ $\mathrm{DH}$ disconnection on cocaine-seeking behavior would depend on re-exposure to the cocaine-paired context immediately prior to the disconnection manipulation. To this end, "no reactivation" control groups were exposed to a novel, unpaired context prior to receiving the BLA/DH disconnection manipulation or $\mathrm{VEH}$ treatment (see experimental timeline in Fig. 3A).

BLA/DH disconnection in the absence of explicit cocaine memory reactivation failed to alter drug context-induced reinstatement of cocaine-seeking behavior, relative to VEH treatment (see Fig. 3B). The $2 \times 2$ ANOVA for active lever responses revealed that exposure to the cocaine-paired context produced an increase in active lever responding in the groups that received $\mathrm{ANI}+\mathrm{B} / \mathrm{M}$ or VEH treatment following exposure to the unpaired context, relative to responding in the extinction context (ANOVA context main effect only, $\left.F_{(1,12)}=23.169, P<0.001\right)$. Furthermore, there was no difference between these groups in active lever responding in the extinction or cocaine-paired context on the test days.

The $2 \times 2$ ANOVA for inactive lever responses revealed that exposure to the cocaine-paired context on the test day elicited a slight increase in inactive lever responding in both groups, relative to responding in the extinction context (see Fig. 3C), and BLA/DH disconnection following exposure to the novel context did not subsequently alter inactive lever responding in the extinction or cocaine-paired context, relative to VEH treatment (ANOVA context main effect only, $\left.F_{(1,12)}=9.096, P<0.020\right)$.

\section{Experiment 3}

Memory reconsolidation inhibitors are expected to impair the target memory trace and, therefore, to exert an enduring effect on
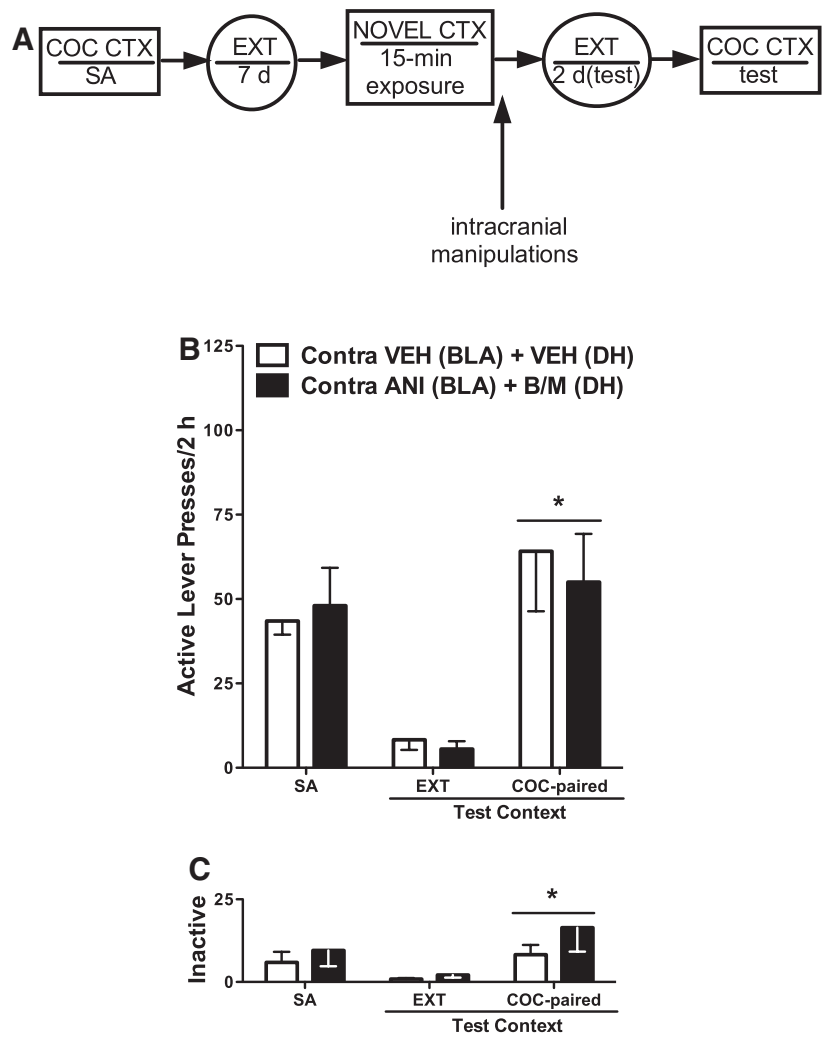

Figure 3. The effects of $B L A / D H$ disconnection on subsequent cocaine seeking are memory reactivation-dependent. $(A)$ Schematic depicting the timeline for Experiment 2 . The procedure was identical to that used in Experiment 1 except that rats were exposed to a novel, unpaired context, instead of the cocaine-paired context, before receiving unilateral microinfusions of $\mathrm{ANI}(62.5 \mu \mathrm{g} / 0.5 \mu \mathrm{L})$ into the BLA plus B/M (1.0/ $0.01 \mathrm{mM} / 0.5 \mu \mathrm{L}$ ) into the contralateral $\mathrm{DH}$, or VEH microinfusions into both brain regions. As in Experiment 1, following the intracranial manipulations, rats received additional extinction training until they reached the extinction criterion ( $\leq 25$ active lever responses/session on two consecutive days). (B) Mean ( \pm SEM) active lever presses during selfadministration (SA; mean of the last three training sessions) and during tests for cocaine-seeking behavior in the extinction context (EXT; the last session preceding the test in the cocaine-paired context) and in the cocaine-paired context (COC-paired). (C) Mean ( \pm SEM) inactive lever presses. $\left(^{*}\right)$ Significant difference relative to responding in the extinction context (ANOVA context main effect, $P<0.05$ ).

conditioned behavior (Alberini et al. 2006; Nader and Wang 2006). Accordingly, we examined whether BLA/DH disconnection following cocaine memory reactivation would disrupt cocaine-seeking behavior after a prolonged drug-free period (i.e., 21-d vs. overnight home cage stay, each followed by a minimum of $2 \mathrm{~d}$ of extinction training prior to the test of drug contextinduced cocaine-seeking behavior) (see experimental timeline in Fig. 4A). During the home cage stay, rats were handled regularly.

BLA/DH disconnection following cocaine memory reactivation attenuated subsequent cocaine-seeking behavior in a context-dependent manner relative to VEH treatment, and this effect was independent of home cage condition (see Fig. 4B). The $2 \times 2 \times 2$ ANOVA for active lever responses indicated significant treatment $\times$ context interaction $\left(F_{(1,29)}=29.881, \quad P<\right.$ $0.001)$, home cage condition main $\left(F_{(1,29)}=5.631, P=0.010\right)$, context main $\left(F_{(1,29)}=136.433, P<0.001\right)$, and treatment main effects $\left(F_{(1,29)}=43.263, P<0.001\right)$. Thus, active lever responding increased following the 21-d home cage stay, consistent with the incubation phenomenon (see Fig. 4B, inset; Tran-Nguyen et al. 

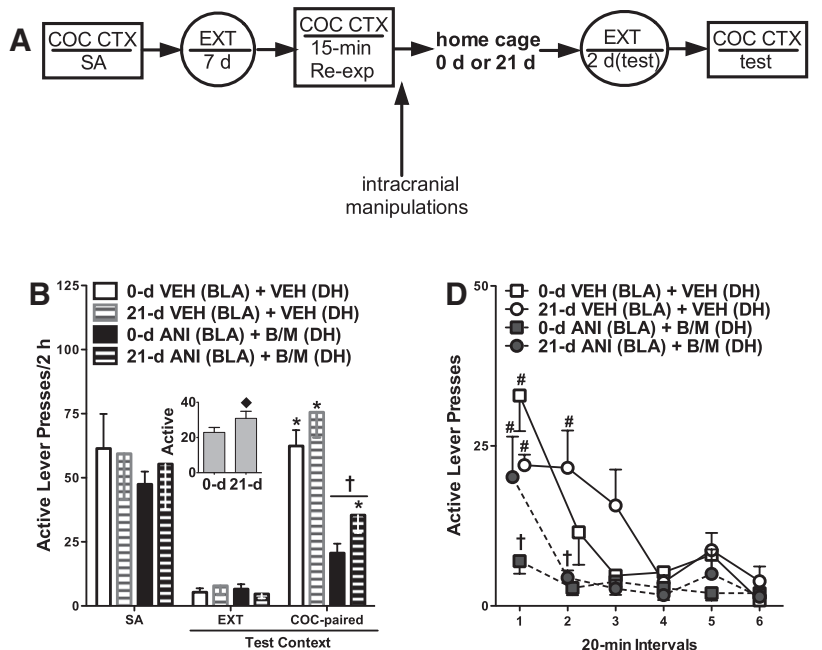

C

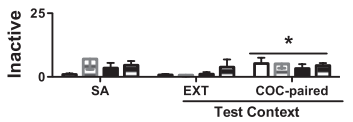

Figure 4. BLA/DH disconnection following cocaine memory reactivation differentially impairs drug context-induced cocaine-seeking behavior after a 0- or 21-d home cage stay. (A) Schematic depicting the timeline for Experiment 3. The procedure was identical to that used in Experiment 1 except that rats remained in their home cages for $0 \mathrm{~d}$ (same groups as in Experiment 1) or $21 \mathrm{~d}$ following unilateral microinfusions of $\mathrm{ANI}$ $(62.5 \mu \mathrm{g} / 0.5 \mu \mathrm{L})$ into the BLA plus B/M $(1.0 / 0.01 \mathrm{mM} / 0.5 \mu \mathrm{L})$ into the contralateral $\mathrm{DH}$, or microinfusions of $\mathrm{VEH}$ into both brain regions. Following the home cage stay, rats received additional extinction training until they reached the extinction criterion ( $<25$ active lever responses/ session on two consecutive days). (B) Mean ( \pm SEM) active lever presses during self-administration (SA; mean of the last three training sessions) and during tests of cocaine-seeking behavior in the extinction context (EXT; the last session preceding the test in the cocaine-paired context), and in the cocaine-paired context (COC-paired). (Inset) Mean active lever presses during testing collapsed across context and treatment. (C) Mean ( \pm SEM) inactive lever presses. $(D)$ The time course of active lever responses (mean \pm SEM) during the test in the cocaine-paired context. $(E)$ The time course of inactive lever responses (mean \pm SEM). ( $\bullet$ ) Significant difference relative to the 0 - $d$ condition (ANOVA home cage condition main effect, $P<0.05)$. (*) Significant difference in responding relative to that in the extinction context (ANOVA context simple main effect, $P<0.05)$. ( $\dagger$ ) Significant difference relative to VEH treatment (ANOVA treatment simple main effect, $P<0.05$ ). (\#) Significant difference relative to all other time intervals $(D$ : 0 -d VEH and 21-d ANI + B/ $M$ groups, ANOVA time simple main effects, $P<0.05$; $E$, ANOVA time main effect, $P<0.05$ ) or relative to intervals 4 and 6 ( $D: 21-d$ VEH group; ANOVA time simple main effect, $P<0.05$ ).

1998; Grimm et al. 2001; Lu et al. 2004). Collapsed across home cage condition, re-exposure to the cocaine-paired context on the test day elicited increased active lever responding in the VEH groups, relative to responding in the extinction context (ANOVA context simple main effect, Tukey test, $P<0.05$ ). Furthermore, the groups that had received BLA/DH disconnection after cocaine memory reactivation subsequently exhibited less active lever responding in the cocaine-paired, but not in the extinction, context relative to the VEH groups (ANOVA treatment simple main effect, Tukey test, $P<0.05$ ).

Time course analysis of active lever responses during the test of drug context-induced cocaine seeking indicated that responding depended on treatment, home cage condition, and time (see Fig. 4D). The ANOVA of active lever responses during the six 20-min time intervals of the test session indicated a significant treatment $\times$ home cage condition $\times$ time interaction effect $\left(F_{(5,140)}=4.465, P=0.001\right)$, as well as significant treatment $\times$ time interaction $\left(F_{(5,140)}=3.304, \quad P=0.008\right)$, time main $\left(F_{(5,140)}=19.702, P<0.001\right)$, treatment main $\left(F_{(1,28)}=39.989\right.$, $P<0.001)$, and home cage condition main effects $\left(F_{(1,28)}=\right.$ 4.343, $P=0.046)$. Active lever responding declined over the course of the test session in the VEH groups; however, the rate of decline differed as a function of home cage condition. Specifically, the 0-d VEH group exhibited less responding during intervals 2-6 relative to interval 1 (ANOVA time simple main effects, Tukey test, $P<0.05$ ). Conversely, the 21 -d VEH group exhibited stable responding during intervals $1-3$, and active lever responding in this group decreased during intervals 4 and 6 relative to intervals 1 and 2 (ANOVA time simple main effect, Tukey test, $P<0.05)$. The 0 - $\mathrm{d}$ ANI $+\mathrm{B} / \mathrm{M}$ group exhibited low levels of responding throughout the test session, and responding in this group was significantly lower than that in the respective 0 -d VEH group during interval 1 (ANOVA treatment simple main effect, Tukey test, $P<0.05$ ). On the other hand, the 21-d ANI + $\mathrm{B} / \mathrm{M}$ group demonstrated high levels of responding during interval 1 such that responding in this group was not different than responding in the respective 21-d VEH group but also did not differ from that in the 0 -d VEH or $0-d$ ANI $+B / M$ groups. Interestingly, however, responding in the 21-d ANI + B/M group rapidly declined such that it was significantly lower than responding in the respective 21-d VEH group during interval 2 (ANOVA treatment simple main effect, Tukey test, $P<0.05$ ).

The $2 \times 2 \times 2$ ANOVA for inactive lever responses indicated that exposure to the cocaine-paired context elicited a slight increase in overall inactive lever responding relative to responding in the extinction context (ANOVA context main effect only, $F_{(1,29)}=7.642, P=0.010$ ) (see Fig. $4 \mathrm{C}$ ). Neither BLA/DH disconnection nor home cage condition altered inactive lever responding in either context. The time course of inactive lever responses during the test of drug context-induced cocaine-seeking behavior revealed that inactive lever responding declined during the session, independent of treatment or home cage condition (ANOVA time main effect only, $F_{(5,140)}=9.527, P<0.001$, interval $1>$ intervals $2-6$, Tukey test, $P<0.05$ ) (Fig. $4 \mathrm{E}$ ).

\section{Discussion}

\section{Critical involvement of intrahemispheric BLA/DH interactions in the reconsolidation of cocaine-related memories that control drug context-induced cocaine-seeking behavior}

To our knowledge, the present study offers the first demonstration that functional interaction between the BLA and DH is required for the reconsolidation of cocaine-related associative memories that underlie the ability of a cocaine-paired environmental context to reinstate extinguished cocaine-seeking behavior. To test for functional interdependence between the BLA and DH, a disconnection procedure was employed. Disconnection of the BLA and $\mathrm{DH}$ at the putative time of memory reconsolidation was achieved by administering unilateral microinfusions of ANI into the $\mathrm{BLA}$ and $\mathrm{B} / \mathrm{M}$ into the contralateral $\mathrm{DH}$ following cocaine memory reactivation. This manipulation was expected to temporarily inhibit intrahemispheric interaction between the BLA and DH in both hemispheres. Conversely, the ipsilateral ANI $+B / M$ control manipulation was expected to spare intrahemispheric information sharing between these brain regions in one hemisphere while eliminating interhemispheric interactions in both hemispheres. Importantly, ipsilateral and contralateral ANI + B/ $\mathrm{M}$ treatment affected the same amount of neural tissue (Olton 
et al. 1982; Gaffan et al. 1993); therefore, unilateral or additive effects of the intra-BLA ANI and intra-DH B/M treatments were expected to manifest similarly following contralateral and ipsilateral administration. In the present study, BLA/DH disconnection with $\mathrm{ANI}+\mathrm{B} / \mathrm{M}$, but not the ipsilateral manipulation with the same treatment, administered immediately after re-exposure to the cocaine-paired context, attenuated subsequent drug context-induced reinstatement of cocaine-seeking behavior relative to VEH treatment (Fig. 2B). Following cocaine memory reactivation, bilateral ANI administration into the posterior caudate putamen or bilateral tetrodotoxin-induced neural inactivation of the trunk region of the somatosensory cortex (i.e., reconsolidation inhibitor manipulations in brain regions dorsally adjacent to the BLA and DH, respectively) fails to alter later drug contextinduced reinstatement (Fuchs et al. 2009; Ramirez et al. 2009). This suggests that the intracranial manipulations in the present study were anatomically selective to the BLA and DH.

Attenuation in cocaine-seeking behavior observed 48-72 h following BLA/DH disconnection did not reflect a protracted $\mathrm{ANI}+\mathrm{B} / \mathrm{M}$-induced motor performance deficit. In strong support of this, in Experiment 2, BLA/DH disconnection with ANI + B/M following exposure to an unpaired context did not alter subsequent cocaine-seeking behavior relative to VEH treatment (see Fig. 3B). Post-memory reactivation treatment with ANI + B/M administered into the BLA plus the contralateral or ipsilateral $\mathrm{DH}$ also failed to suppress general motor activity in a novel context (see Supplementary Fig. S1). Furthermore, ANI + B/M treatment failed to inhibit lever responding in the extinction context or inactive lever responding in either context (see Fig. 2B,C). These findings indicate that the attenuation in cocaine-seeking behavior produced by BLA/DH disconnection following cocaine memory reactivation was not due to ANI $+\mathrm{B}$ / M-induced hypoactivity or nonspecific impairment in instrumental motor behavior.

An important corollary of the memory reconsolidation hypothesis is that bona fide memory reconsolidation deficits depend on memory reactivation (Lewis 1979; Nader et al. 2000b; Sara 2000). Satisfying this requirement, BLA/DH disconnection inhibited subsequent cocaine-seeking behavior when it was induced following re-exposure to the cocaine-paired context, but not an unpaired context (i.e., in the absence of explicit cocaine-related memory reactivation) (see Fig. 3B). We have also demonstrated previously that functional disconnection of the BLA and DH at the time of reinstatement testing disrupts the expression of drug context-induced cocaine seeking (Fuchs et al. 2007). Together, these findings suggest that intrahemispheric communication between the BLA and DH critically contributes not only to the reconsolidation of reactivated cocaine-related associative memories into long-term memory storage, but also to the recall or utilization of cocaine-related associative memories in general. Thus, the BLA-DH circuitry tightly regulates the control of environmental stimuli over cocaine-seeking behavior.

While the effects of BLA/DH disconnection were specific to reactivated cocaine-related memories, implying a memory reconsolidation deficit, contralateral $\mathrm{ANI}+\mathrm{B} / \mathrm{M}$ treatment could have directly impaired the labile, post-reactivation short-term memory (PR-STM) that is to be reconsolidated. PR-STM deficits can be determined by measuring conditioned behavior during the period of putative memory lability (i.e., within $4-6 \mathrm{~h}$ of memory reactivation) (Nader et al. 2000a). The prolonged half-life of $\mathrm{B} / \mathrm{M}$ ( 24 h) (Martin and Ghez 1993, 1999) prevented such assessment of PR-STM in the present study given that BM-induced BLA/DH disconnection inhibits the expression of drug context-induced cocaine seeking behavior per se (Fuchs et al. 2007). However, somewhat mitigating the possibility that BLA/DH disconnection impaired memory reconsolidation solely by disrupting PR-STM, bilateral intra-BLA ANI treatment fails to disrupt PR-STM in the fear conditioning paradigm (Nader et al. 2000a).

In conclusion, cocaine-related memory reconsolidation likely involves interactions between the BLA and DH, similar to initial memory consolidation (for review, see Richter-Levin and Akirav 2001). Communication between the BLA and DH facilitates the consolidation of memories that guide hippocampusdependent behaviors, including maze performance (Packard et al. 1994; Packard and Teather 1998), as well as active and passive avoidance (Roozendaal and McGaugh 1997; Rezayof et al. 2011). Specifically, the BLA appears to play a modulatory role in DH-dependent memory consolidation. Remarkably, however, BLA/DH interactions of a different nature bring about memory reconsolidation in the contextual reinstatement paradigm. The failure of post-reactivation ANI treatment in the DH to impair cocaine-seeking behavior (Ramirez et al. 2009; also see Biedenkapp and Rudy 2004) suggests that the DH is not the locus of memory re-stabilization per se, since ANI-sensitive processes are considered to be necessary for memory reconsolidation (Tronson and Taylor 2007; Nader and Einarsson 2010). Nevertheless, the present study demonstrates that intrahemispheric communication between the DH and the BLA is required for the reconsolidation of context-response-cocaine associative memories that regulate drug context-induced cocaine-seeking behavior. Accordingly, we propose that cocaine-related associative memories undergo ANI-sensitive re-stabilization in the BLA, and the DH may contribute to the maintenance of PR-STM or the establishment of retrieval links in the BLA or elsewhere in the brain during the time of memory reconsolidation. The necessary communication between the BLA and DH may occur via sparse monosynaptic connections between the BLA and DH (Pikkarainen et al. 1999) or via multisynaptic connections that involve other brain regions. The entorhinal cortex may serve as a relay in this circuit as this brain region has reciprocal connections with both the BLA and DH (Finch et al. 1986; Witter et al. 1989, Van Groen and Wyss 1990; McDonald and Mascagni 1997; Fanselow and Dong 2010).

\section{Time-dependent effects of post-reactivation BLA/DH disconnection on drug context-induced cocaine-seeking behavior and implications for the treatment of drug addiction}

Inhibition of memory reconsolidation is predicted to selectively impair the memory trace and, consequently, elicit prolonged interference with conditioned behavior (for review, see Nader 2003; Amaral et al. 2008), and this property is desirable from a treatment perspective. In fact, it has been suggested that disrupting the reconsolidation of maladaptive associative memories may be useful for the treatment of psychiatric disorders, including post-traumatic stress disorder, phobias, obsessive-compulsive disorder, and addictive behavior (Diergaarde et al. 2008; Taylor et al. 2009; Milton and Everitt 2010). In this respect, it is encouraging that BLA/DH disconnection attenuated overall drug contextinduced cocaine-seeking behavior to a similar extent after a 21-d vs. overnight home cage stay and approximately two extinction training days, relative to VEH (Fig. 4B). Thus, memory reconsolidation inhibitors may open a therapeutic window by impairing memory traces that underlie the incentive motivational effects of drug-associated environmental stimuli even though it is unlikely they prevent the resumption of drug-taking behaviors if drug reinforcement contingencies are restored.

Interestingly, the inhibitory effects of BLA/DH disconnection on drug-context-induced cocaine-seeking behavior were apparent only after the first 20-min interval of the test session 
relative to VEH treatment (Fig. 4D). It is unlikely that cocaineseeking behavior during the first 20-min interval of the test session in the BLA/DH disconnection group reflected spontaneous recovery, the return of a previously extinguished response with time (Domjan 1998; Eisenberg et al. 2003; Bouton 2004), given that manipulations of the DH (Corcoran et al. 2005; Bevilaqua et al. 2007) or BLA (Fuchs et al. 2006; McLaughlin and Floresco 2007; Baldi and Bucherelli 2010) impair, rather than enhance, extinction learning. Rather, it probably signifies the maturation-thus, delayed availability-of alternate memory traces (McClelland et al. 1995; Frankland and Bontempi 2005; Frankland et al. 2006; Amaral et al. 2008), or the re-strengthening of memory traces weakened by $\mathrm{ANI}+\mathrm{B} / \mathrm{M}$ treatment in the absence of external cue exposure during abstinence. Consistent with the idea of residual memory traces, humans exhibit impaired cue-induced fear memory but intact declarative memory of CS-fear contingency following memory reconsolidation inhibition using beta adrenergic receptor antagonism (Kindt et al. 2009). Similar to declarative memories, the putative residual memories in the present study failed to elicit sustained motivated behavior.

The strengthening of drug-related associative memories may be a mechanism for incubation, the well-documented augmentation of drug-seeking behavior after a period of abstinence that has been implicated in the transition from casual drug use to compulsive drug-seeking and drug-taking behaviors (Tran-Nguyen et al. 1998; Grimm et al. 2001; Thomas et al. 2008). In support of this idea, repetitive reflection on drug-related memories predicts future increases in substance abuse symptoms in humans (Nolen-Hoeksema et al. 2007). Consistent with an incubation effect, the groups that remained in their home cages for $21 \mathrm{~d}$ following cocaine memory reactivation and were tested on approximately post-cocaine day 32 exhibited more robust context-induced cocaine-seeking behavior than overnight home cage controls (see Fig. 4B, inset). This incubation effect was modest relative to that observed in other studies (see Grimm et al. 2001; Lu et al. 2004), likely due to extensive extinction training (Berglind et al. 2007; Kelamangalath and Wagner 2009). Incubation manifested as impairment in the extinction of drug context-induced cocaine-seeking behavior during the nonreinforced test session (i.e., perseveration) following the 21 -d vs. overnight home cage stay (see Fig. 4D). Remarkably, contralateral $\mathrm{ANI}+\mathrm{B} / \mathrm{M}$ treatment reversed the incubation-related perseveration in cocaine-seeking behavior. These data suggest that, during early withdrawal, the integrity of memory traces that encode context-response-cocaine associations may be necessary for the subsequent development of incubation, consistent with the idea that incubation may involve the strengthening of associative memory traces over time.

In conclusion, $\mathrm{BLA} / \mathrm{DH}$ disconnection at the time of cocaine memory reconsolidation had a robust inhibitory effect on the motivational effects of a cocaine-paired environmental context when evaluated $18 \mathrm{~d}$ after initial memory consolidation and after extensive memory reconsolidation during the 10-d cocaine selfadministration training regimen (also see Lee et al. 2006). Some recovery of cocaine-seeking behavior was observed following an extended drug-free period (i.e., $39 \mathrm{~d}$ after initial memory consolidation), likely due to the availability of new or residual cocaine-related associative memories. However, importantly, BLA/DH disconnection attenuated cocaine- seeking behavior even after the development of incubation. These findings confirm that the BLA and DH interact to control cocaine-related memory reconsolidation and drug context-induced cocaine-seeking behavior and support the idea that targeting memory reconsolidation to combat environmentally induced relapse may be a worthwhile treatment option for recovering drug addicts.

\section{Materials and Methods}

\section{Animals}

Male Sprague-Dawley rats (Charles-River, Wilmington, MA, $n=$ 61) were maintained in a temperature- and humidity-controlled vivarium on a reversed light-dark cycle. Rats weighed between 275-300 g at the start of the experiment and were maintained on 20-25 g of rat chow per day with water available ad libitum. The housing and treatment of animals used in the study followed the National Research Council's Guide for the Care and Use of Laboratory Rats (Institute of Laboratory Animal Resources on Life Sciences) and were approved by the Institutional Animal Care and Use Committee of the University of North Carolina at Chapel Hill.

\section{Food training}

To accelerate the acquisition of cocaine self-administration, rats were initially trained to press a lever under a fixed-ratio 1 schedule of food reinforcement (i.e., each active lever press resulted in the delivery of a $45-\mathrm{mg}$ pellet [Noyes]) during a 16-h session overnight. Food training was conducted in standard sound-attenuated operant conditioning chambers $(26 \times 27 \times 27 \mathrm{~cm})$ (Coulbourn Instruments). During the session, active lever responses were reinforced with the delivery of food pellets while inactive lever responses had no programmed consequences. The contextual stimuli that were used during cocaine self-administration and extinction training were not present in the chambers during food training.

\section{Surgery}

Forty-eight hours after food training, rats were fully anesthetized with ketamine hydrochloride and xylazine $(66.6 \mathrm{mg} / \mathrm{kg}$ and $1.33 \mathrm{mg} / \mathrm{kg}$, i.p, respectively). Intravenous catheters were constructed in-house, as described previously (Fuchs et al. 2007). The catheter was inserted into the right jugular vein and ran subcutaneously to the back where it exited between the scapulae. Immediately after the catheterization surgery, rats were placed into a stereotaxic instrument (Stoelting). Twenty-six gauge stainless steel guide cannulae (Plastics One) were aimed unilaterally at the right or left BLA $(-2.7 \mathrm{~mm} \mathrm{AP}, \pm 5.2 \mathrm{~mm} \mathrm{ML},-6.8 \mathrm{~mm} \mathrm{DV}$, relative to bregma) and at the contralateral or ipsilateral $\mathrm{DH}$ (angled rostrally by $15^{\circ}$ to accommodate the BLA cannula, $-4.1 \mathrm{~mm} \mathrm{AP}, \pm 2.1 \mathrm{ML},-2.7 \mathrm{~mm} \mathrm{DV}$, relative to bregma). Stainless steel screws and cranioplastic cement secured the guide cannulae to the skull. Stylets (Plastics One) and Tygon caps sealed the guide cannulae and catheter, respectively, in order to prevent occlusion.

Rats were given $5 \mathrm{~d}$ of post-operative recovery before the start of the experiment. To maintain catheter patency during this time, the catheters were flushed through daily with $0.1 \mathrm{~mL}$ of an antibiotic solution of cefazolin $(10.0 \mathrm{mg} / \mathrm{mL}$; Schein Pharmaceuticals) dissolved in heparinized saline $(70 \mathrm{U} / \mathrm{mL}$; Baxter Health Care Corp.) followed by $0.1 \mathrm{~mL}$ of heparinized saline $(70 \mathrm{U} / \mathrm{mL})$. During self-administration training, catheters were flushed through with $0.1 \mathrm{~mL}$ of heparinized saline $(10 \mathrm{U} / \mathrm{mL})$ before each session and with $0.1 \mathrm{~mL}$ of the cefazolin solution and $0.1 \mathrm{~mL}$ of heparinized saline $(70 \mathrm{U} / \mathrm{mL})$ after each session. Catheter patency was assessed before the first self-administration session and periodically during the experiment, using propofol $(1 \mathrm{mg} / 0.1 \mathrm{~mL}$, i.v.; Eli Abbott Lab), which produces temporary loss of muscle tone when administered intravenously.

\section{Cocaine self-administration training}

Self-administration training was conducted in standard operant conditioning chambers configured to one of two distinctly different contexts. Context 1 contained a continuous red house light opposite to the active lever, intermittent pure tone $(80 \mathrm{~dB}$, $1 \mathrm{kHz} ; 2 \mathrm{sec}$ on, $2 \mathrm{sec}$ off), pine-scented air freshener strip $(4.5 \mathrm{~cm} \times 2 \mathrm{~cm}$; Car Freshener Corp.), and a wire mesh floor $(26 \mathrm{~cm} \times 27 \mathrm{~cm})$. Context 2 contained an intermittent white 
stimulus light above the inactive lever ( 2 sec on, 4 sec off), continuous pure tone $(75 \mathrm{~dB}, 2.5 \mathrm{kHz})$, vanilla-scented air freshener strip $(4.5 \times 2 \mathrm{~cm}$, Sopus Products), and a slanted ceramic tile wall that bisected a bar floor $(19 \mathrm{~cm} \times 27 \mathrm{~cm})$. Rats were randomly assigned to Context 1 or Context 2 and allowed to self-administer cocaine in that context under a fixed-ratio 1 schedule of cocaine reinforcement (cocaine hydrochloride; $0.15 \mathrm{mg} / 0.05 \mathrm{~mL}$ per infusion, i.v.; NIDA). Training took place during daily 2-h sessions in their dark cycle. The rats' catheters were connected to an infusion apparatus (Coulbourn Instruments) via polyethylene 20 tubing and liquid swivels (Instech). Active lever responses activated an infusion pump for 2 sec. Each infusion was immediately followed by a 20 -sec time-out period, during which active lever responses had no programmed consequences. Responses on the other (inactive) lever were recorded but had no programmed consequences. Training continued until rats reached a criterion of $\geq 10$ cocaine infusions per session during at least 10 sessions. Data collection and reinforcer delivery were controlled using Graphic State Notation software version 2.102 (Coulbourn).

\section{Extinction training}

After reaching the acquisition criterion, rats received seven daily 2-h extinction training sessions. Rats that self-administered cocaine in Context 1 were placed into Context 2 for extinction training, and vice versa. During the extinction sessions, active and inactive lever responses were recorded but had no programmed consequences. Immediately after the fourth extinction session, rats were adapted to the intracranial microinfusion procedure. To this end, stainless steel injection cannulae were inserted into the guide cannulae to a depth of either $1 \mathrm{~mm}(\mathrm{DH})$ or $2 \mathrm{~mm}$ (BLA) below the tip of the guide cannulae. The injector cannulae remained in place for $4 \mathrm{~min}$, but no fluid was infused during the adaptation procedure.

\section{Experiment 1: Effects of BLA/DH disconnection on cocaine memory reconsolidation}

Experiment 1 was designed to evaluate whether functional disconnection of the BLA and DH following cocaine memory reactivation would impair subsequent drug context-induced cocaine seeking. A schematic representing the experimental timeline is provided in Figure 2A.

\section{Memory reactivation}

After the final day of extinction training, rats were re-exposed to the cocaine-paired context for $15 \mathrm{~min}$ in order to destabilize cocaine-related memories (Lewis 1979; Nader et al. 2000b; Tronson and Taylor 2007). This session length was selected because it is sufficient to reactivate cocaine-related associative memories without producing significant behavioral extinction (Fuchs et al. 2009). During the memory reactivation session, rats were connected to the infusion apparatus, but fluids were not infused, and responding on the active and inactive levers had no programmed consequences.

\section{Intracranial manipulations}

Immediately after the memory reactivation session, rats received a unilateral microinfusion of anisomycin $(62.5 \mu \mathrm{g} / 0.5 \mu \mathrm{L})$ into the left or right BLA plus a unilateral microinfusion of the GABA agonists baclofen/muscimol $(1.0 / 0.01 \mathrm{mM} / 0.5 \mu \mathrm{L})$ into the contralateral or ipsilateral $\mathrm{DH}$. The dose of ANI used was selected based on our previous research demonstrating that when microinfused bilaterally into the BLA, but not the overlying posterior caudate-putamen $(\mathrm{pCPu})$, this dose was sufficient to disrupt cocaine memory reconsolidation in our model (Fuchs et al. 2009). While tetrodotoxin was used in our previous study to demonstrate the involvement of the DH but not the overlying trunk region of the somatosensory cortex (SStr), in cocaine memory reconsolidation (Ramirez et al. 2009), B/M was used in the present disconnection study in order to selectively inhibit neural activity within the DH while sparing fibers of passage (van Duuren et al.
2007). The dose of $\mathrm{B} / \mathrm{M}$ was selected based on an earlier BLA/ DH disconnection study (Fuchs et al. 2007). Vehicle control groups received phosphate buffered saline $(0.5 \mu \mathrm{L})$ unilaterally into the BLA plus the contralateral or ipsilateral DH. Assignment to treatment conditions was counterbalanced based on previous cocaine intake. During the microinjection procedure, the injection cannulae were connected to Hamilton syringes (Hamilton Co.) that were mounted on a microdrive pump (KD Scientific). Microinfusions were delivered over $2 \mathrm{~min}$, and the injection cannulae were left in place for $1 \mathrm{~min}$ before and after the microinfusion in order to limit drug diffusion, as described previously (Fuchs et al. 2007).

\section{Extinction training and test of drug context-induced cocaine seeking}

Starting on the day following the memory reactivation session, rats received additional daily 2 -h extinction training sessions until they reached an extinction criterion (i.e., $\leq 25$ active lever responses per session on a minimum of two consecutive days). Twenty-four hours later, rats were returned to the cocaine-paired context for a 2-h test of cocaine-seeking behavior. During the test session, active and inactive lever presses were recorded but had no programmed consequences.

\section{General motor activity testing}

Intracranial manipulations can alter cocaine-seeking behavior by impairing general motor activity. This was unlikely in the present study since testing occurred at a minimum of $72 \mathrm{~h}$ following the intracranial manipulation. Nonetheless, the possible protracted effects of contralateral and ipsilateral ANI $+\mathrm{B} / \mathrm{M}$ and VEH treatments on motor activity were assessed $24 \mathrm{~h}$ after the reinstatement test in Experiment 1 . The general motor activity test took place in a novel Plexiglas chamber $(42 \times 20 \times 20 \mathrm{~cm})$ that was equipped with an array of eight photodetectors. A computerized activity system (San Diego Instruments) recorded photobeam breaks resulting from the movement of rats in the chamber during a 2 -h session.

\section{Experiment 2: Effects of BLA/DH disconnection in the absence of explicit cocaine memory reactivation}

The memory reconsolidation theory posits that reconsolidation inhibitors selectively target memories that have been rendered labile by reactivation (Nader et al. 2000b; Alberini et al. 2006; Tronson and Taylor 2007). Experiment 2 was designed to evaluate whether the effect observed in Experiment 1 would be similarly observed in the absence of explicit cocaine memory reactivation. The experimental protocol was identical to that in Experiment 1 except that the groups were placed into a novel, unpaired context for $15 \mathrm{~min}$ prior to receiving ipsilateral or contralateral $\mathrm{ANI}+\mathrm{B}$ / $\mathrm{M}$ or $\mathrm{VEH}+\mathrm{VEH}$ microinfusions into the BLA and DH, respectively. The unpaired context contained continuous white stimulus lights above each lever, a continuous red house light opposite to the active lever, a continuous complex tone $(80 \mathrm{~dB}$, alternating between $1,1.5$, and $2.5 \mathrm{kHz}$ at $1 \mathrm{sec}$ intervals), a citrus-scented air freshener strip $(4.5 \times 2 \mathrm{~cm}$, Locasmarts LLC), and ceramic tile flooring $(26 \mathrm{~cm} \times 27 \mathrm{~cm})$. A schematic representing the experimental timeline for Experiment 2 is provided in Figure 3A.

\section{Experiment 3: Time-dependent effects of post-memory reactivation BLA/DH disconnection on drug context-induced cocaine seeking}

Genuine memory reconsolidation deficits are characterized by the loss or impairment of the memory trace, and in turn, long-lasting behavioral deficit (Nader and Wang 2006). Experiment 3 was designed to evaluate the effects of BLA/DH disconnection, administered following re-exposure to a cocaine-paired context, on the ability of the cocaine-paired context to reinstate cocaine-seeking behavior after an extended drug-free period. 
All protocols in this experiment were identical to those used in Experiments 1 and 2, except that rats were assigned to stay in their home cages for $21 \mathrm{~d}$ following the memory reactivation session and intracranial microinfusions. During the home cage stay, rats were handled regularly. A schematic representing the experimental timeline is provided in Figure 4A. The contralateral BLA/ $\mathrm{DH}$-cannulated groups from Experiment 1 served as 0-d (overnight) home cage control groups in Experiment 3.

\section{Histology}

After the last experimental session, rats were overdosed with ketamine hydrochloride and xylazine $(66.6$ and $1.3 \mathrm{mg} / \mathrm{kg}$, i.v., or 199.8 and $3.9 \mathrm{mg} / \mathrm{kg}$, i.p., respectively, depending on catheter patency). They were then transcardially perfused with $1 \times$ phosphate-buffered saline (Fisher Scientific) and 10\% formaldehyde solution (Sigma). Brains were dissected out and stored in $10 \%$ formaldehyde solution until they were sectioned in the coronal plane at a thickness of $75 \mu \mathrm{m}$ using a vibratome. The sections were mounted onto gelatin-coated slides and stained using cresyl violet (Kodak). Cannula placements were verified using light microscopy. The most ventral portion of each cannula tract was mapped onto schematics of appropriate plates from the rat brain atlas (Paxinos and Watson 1997).

\section{Data analysis}

Separate ANOVAs were conducted to test for possible pre-existing differences in cocaine intake as well as active and inactive lever responding during cocaine self-administration training (mean of last $3 \mathrm{~d}$ ), extinction training (day 1, day 7), and during the memory reactivation session for the groups of rats in Experiments 1, 2, and 3 . In these ANOVAs, group was included as a between-subjects factor, and time (extinction day 1, extinction day 7) was included as a within-subjects factor, as appropriate. Pearson $r$ correlation coefficients were calculated to examine the relationship between active lever responding during the memory reactivation session and during the test of drug context-induced cocaine-seeking behavior.

Separate mixed-factorial ANOVAs were conducted to examine the effects of post-reactivation manipulations on the number of days required to reach the extinction criterion, on active and inactive lever responses on the test days in the cocaine-paired and extinction contexts (last extinction session before the test in the cocaine-paired context), and on motor activity. In these ANOVAs, treatment $(\mathrm{VEH}+\mathrm{VEH}, \mathrm{ANI}+\mathrm{B} / \mathrm{M})$, surgery type (ipsilateral, contralateral), and home cage condition $(0 \mathrm{~d}, 21 \mathrm{~d})$ were included as between-subjects factors, while context (extinction, cocaine-paired) and time (six 20-min intervals) were included as within-subjects factors as appropriate. Significant main and interaction effects were further probed using post-hoc Tukey tests. In addition, the potential hemispheric laterality of significant effects was examined using $t$-tests separately because the variables BLA hemisphere and DH hemisphere were not orthogonal. Alpha was set at 0.05 .

\section{Acknowledgments}

We thank Albert Newsome for excellent technical assistance and Drs. Donna Ramirez and Amy Arguello for comments on an earlier version of this manuscript. Portions of this work were presented at the 2010 annual meeting of the College on Problems of Drug Dependence and the 2010 annual meeting of the Society for Neuroscience. This work was supported by NIDA R01 DA017673, NIDA R01 DA025646, NIDA T32 DA07244, and NIMH T32 NS007431.

\section{References}

Alberini CM, Milekic MH, Tronel S. 2006. Mechanisms of memory stabilization and de-stabilization. Cell Mol Life Sci 63: 999-1008.

Alleweireldt AT, Weber SM, Neisewander JL. 2001. Passive exposure to a contextual discriminative stimulus reinstates cocaine-seeking behavior in rats. Pharmacol Biochem Behav 69: 555-560.
Amaral OB, Osan R, Roesler R, Tort ABL. 2008. A synaptic reinforcement-based model for transient amnesia following disruptions of memory consolidation and reconsolidation. Hippocampus 18: 584-601.

Baldi E, Bucherelli C. 2010. Substantia nigra, nucleus basalis, magnocellularis and basolateral amygdala roles in extinction of contextual fear conditioning in rat. Neurobiol Learn Mem 94: 199-205.

Berglind WJ, See RE, Fuchs RA, Ghee SM, Whitfield TW Jr, Miller SW, McGinty JF. 2007. A BDNF infusion into the medial prefrontal cortex suppresses cocaine seeking in rats. Eur J Neurosci 26: 757-766.

Bernardi RE, Lattal KM, Berger SP. 2006. Post-retrieval propranolol disrupts a cocaine conditioned place preference. Neuroreport 17: 1443-1447.

Bernardi RE, Ryabinin AE, Berger SP, Lattal KM. 2009. Post-retrieval disruption of a cocaine conditioned place preference by systemic and intrabasolateral amygdala $\beta_{2}$ and $\alpha_{1}$-adrenergic antagonists. Learn Mem 16: $777-789$

Bevilaqua LR, Rossato JI, Clarke JH, Medina JH, Izquierdo I, Cammarota M. 2007. Inhibition of c-Jun N-terminal kinase in the CA1 region of the dorsal hippocampus blocks extinction of inhibitory avoidance memory. Behav Pharmacol 18: 483-489.

Biedenkapp JC, Rudy JW. 2004. Contextual memories and reactivation: Constraints on the reconsolidation hypothesis. Behav Neurosci 118: 956-964.

Bouton ME. 2004. Context and behavioral processes in extinction. Learn Mem 11: $485-494$.

Childress A, Ehrman R, McLellan AT, O’Brien C. 1988. Conditioned craving and arousal in cocaine addiction: A preliminary report. NIDA Research Monogr 81: 74-80.

Corcoran KA, Desmond TJ, Frey KA, Maren S. 2005. Hippocampal inactivation disrupts the acquisition and contextual encoding of fear extinction. J Neurosci 28: 8978-8987.

Crombag HS, Bossert JM, Koya E, Shaham Y. 2008. Context-induced relapse to drug seeking: A review. Phil Trans R Soc B 363: 3233-3243.

Diergaarde L, Schoffelmeer AN, De Vries TJ. 2008. Pharmacologica manipulation of memory reconsolidation: Towards a novel treatment of pathogenic memories. Eur J Pharmacol 13: 453-457.

Domjan M. 1998. The principles of learning and behavior, 4th ed. Brooks/ Cole, Pacific Grove, CA.

Eisenberg M, Kobilo T, Berman DE, Dudai Y. 2003. Stability of retrieved memory: Inverse correlation with trace dominance. Science 22: 1102-1104.

Fanselow MS, Dong HW. 2010. Are the dorsal and ventral hippocampus functionally distinct? Neuron 65: 7-19.

Finch DM, Wong EE, Derian EL, Chen X, Nowlin-Finch NL, Brothers LA. 1986. Neurophysiology of limbic system pathways in the rat: Projections from the amygdala to the entorhinal cortex. Brain Res 370: $273-284$.

Foltin RW, Haney M. 2000. Conditioned effects of environmental stimuli paired with smoked cocaine in humans. Psychopharmacology (Berl) 149: 24-33.

Frankland PW, Bontempi B. 2005. The organization of recent and remote memories. Nature Rev Neurosci 6: 119-130.

Frankland PW, Ding HK, Takahashi E, Suzuki A, Kida S, Silva AJ. 2006. Stability of recent and remote contextual fear memory. Learn Mem 13: $451-457$.

Fuchs RA, Weber SM, Rice HJ, Neisewander JL. 2002. Effects of excitotoxic lesions of the basolateral amygdala on cocaine-seeking behavior and cocaine conditioned place preference in rats. Brain Res 929: $15-25$.

Fuchs RA, Evans KA, Ledford CC, Parker MP, Case JM, Mehta RH, See RE. 2005. The role of the dorsomedial prefrontal cortex, basolateral amygdala, and dorsal hippocampus in contextual reinstatement of cocaine seeking in rats. Neuropsychopharmacology 30: 296-309.

Fuchs RA, Feltenstein MW, See RE. 2006. The role of the basolateral amygdala in stimulus-reward memory and extinction memory consolidation and in subsequent condition cued reinstatement of cocaine seeking. Eur J Neurosci 23: 2809-2813.

Fuchs RA, Eaddy JL, Su ZI, Bell GH. 2007. Interactions of the basolateral amygdala with the dorsal hippocampus and dorsomedial prefrontal cortex regulate drug context-induced reinstatement of cocaine-seeking in rats. Eur J Neurosci 26: 487-489.

Fuchs RA, Bell GH, Ramirez DR, Eaddy JL, Su ZI. 2009. Basolateral amygdala involvement in memory reconsolidation processes that facilitate drug context-induced cocaine seeking. Eur J Neurosci 30: 889-900.

Gaffan D, Murray EA, Fabre-Thorpe M. 1993. Interaction of the amygdala with the frontal lobe in reward memory. Eur J Neurosci 5: 968-975.

Gold PE. 2008. Protein synthesis inhibition and memory: Formation vs. amnesia. Neurobiol Learn Mem 89: 201-211.

Grimm JW, Hope BT, Wise RA, Shaham Y. 2001. Neuroadaptation. Incubation of cocaine craving after withdrawal. Nature 412: 141-142. 
Kantak KM, Black Y, Valencia E, Green-Jordan K, Eichenbaum HB. 2002. Dissociable effects of lidocaine inactivation on the rostral and caudal basolateral amygdala on the maintenance and reinstatement of cocaine-seeking behavior in rats. J Neurosci 22: 1126-1136.

Kearns DN, Weiss SJ. 2007. Contextual renewal of cocaine seeking in rats and its attenuation by the conditioned effects of an alternate reinforcer. Drug Alcohol Depend 90: 193-202.

Kelamangalath L, Wagner JJ. 2009. Effects of abstinence or extinction on cocaine-seeking as a function of withdrawal duration. Behav Pharmacol 20: $195-203$.

Kindt M, Soeter M, Vervliet B. 2009. Beyond extinction: Erasing human fear responses and preventing the return of fear. Nature 12: 256-258.

Lee JL, Di Ciano P, Thomas KL, Everitt BJ. 2005. Disrupting reconsolidation of drug memories reduces cocaine seeking behavior. Neuron 47: 795-801.

Lee JL, Milton AL, Everitt BJ. 2006. Cue-induced cocaine seeking and relapse are reduced by disruption of drug memory reconsolidation. $J$ Neurosci 26: 5881-5887.

Lewis DJ. 1979. Psychobiology of active and inactive memory. Psychol Bull 86: $1054-1083$.

Li F, Xue Y, Wang J, Fang Q, Li Y, Zhu W, He Y, Liu J, Xue L, Shaham Y, et al. 2010. Basolateral amygdala cdk5 activity mediates consolidation and reconsolidation of memories for cocaine cues. J Neurosci 30: 10351-10359.

Lu L, Grimm JW, Hope BT, Shaham Y. 2004. Incubation of cocaine craving after withdrawal: A review of preclinical data. Neuropharmacology 47: $214-226$.

Mamiya N, Fukushima H, Suzuki A, Matsuyama Z, Homma S, Frankland PW, Kida S. 2009. Brain region-specific gene expression activation required for reconsolidation and extinction of contextual fear memory. J Neurosci 29: 402-413.

Martin JH, Ghez C. 1993. Differential impairments in reaching and grasping produced by local inactivation within the forelimb representation of the motor cortex in the cat. Exp Brain Res 94: $429-443$.

Martin JH, Ghez C. 1999. Pharmacological inactivation in the analysis of the central control of movement. J Neurosci Methods 86: $145-159$.

McClelland JL, McNaughton BL, O'Reilly RC. 1995. Why are there complementary learning systems in the hippocampus and neocortex: Insights from the successes and failures of connectionist models of learning and memory. Psychol Review 102: 419-457.

McDonald AJ, Mascagni F. 1997. Projections of the lateral entorhinal cortex to the amygdala: A Phaseolus vulgaris leucoagglutinin study in the rat. Neuroscience 77: 449-459.

McLaughlin RJ, Floresco SB. 2007. The role of different subregions of the basolateral amygdala in cue-induced reinstatement and extinction of food-seeking behavior. Neuroscience 146: 1484-1494.

Meil WM, See RE. 1997. Lesions of the basolateral amygdala abolish the ability of drug-associated cues to reinstate responding during withdrawal from self-administered cocaine. Behav Brain Res 87: $139-148$.

Milekic MH, Brown SD, Castellini C, Alberini CM. 2006. Persistent disruption of an established morphine conditioned place preference. J Neurosci 26: 3010-3020.

Milekic MH, Pollonini G, Alberini CM. 2007. Temporal requirement of $\mathrm{C} / \mathrm{EBP} \beta$ in the amygdala following reactivation but not acquisition of inhibitory avoidance. Learn Mem 14: 504-511.

Miller CA, Marshall JF. 2005. Molecular substrates for retrieval and reconsolidation of cocaine-associated contextual memory. Neuron 47: 873-884.

Milton AL, Everitt BJ. 2010. The psychological and neurochemical mechanisms of drug memory reconsolidation: Implications for the treatment of addiction. Eur J Neurosci 31: 2308-2319.

Milton AL, Lee JL, Butler VJ, Gardner R, Everitt BJ. 2008. Intra-amygdala and systemic antagonism of NMDA receptors prevents the reconsolidation of drug-associated memory and impairs subsequently both novel and previously acquired drug-seeking behaviors. J Neurosci 28: $8230-8237$.

Misanin JR, Miller RR, Lewis DJ. 1968. Retrograde amnesia produced by electroconvulsive shock after reactivation of a consolidated memory trace. Science 160: $554-555$.

Nader K. 2003. Memory traces unbound. Trends Neurosci 26: 65-72.

Nader K, Einarsson EO. 2010. Memory reconsolidation: An update. Ann NY Acad Sci 1191: 27-41.

Nader K, Wang S. 2006. Fading in. Learn Mem 13: 530-535.
Nader K, Schafe GE, LeDoux JE. 2000a. Fear memories require protein synthesis in the amygdala for reconsolidation after retrieval. Nature 406: $722-726$.

Nader K, Schafe GE, LeDoux JE. 2000b. The labile nature of consolidation theory. Nat Rev Neurosci 1: 216-219.

Narayanan RT, Seidenbecher T, Sangha S, Stork O, Pape H. 2007. Theta resynchronization during reconsolidation of remote contextual fear memory. Neuroreport 18: 1107-1111.

Nolen-Hoeksema S, Stice E, Wade E, Bohon C. 2007. Reciprocal relations between rumination and bulimic, substance abuse, and depressive symptoms in female adolescents. J Abnormal Psych 116: 198-207.

O’Brien C, Childress AR, Ehrman R, Robbins S, McLellan AT. 1992. Conditioning mechanisms in drug dependence. Clin Neuropharmacol 15: $66 \mathrm{~A}-67 \mathrm{~A}$.

Olton DS, Walker JA, Wolf WA. 1982. A disconnection analysis of hippocampal function. Brain Res 233: 241-253.

Packard MG, Teather LA. 1998. Amygdala modulation of multiple memory system: Hippocampus and caudate-putamen. Neurobiol Learn Mem 69: 163-203.

Packard MG, Cahill L, McGaugh JL. 1994. Amygdala modulation of hippocampal-dependent and caudate nucleus-dependent memory processes. Proc Natl Acad Sci 91: 8477-8481.

Paxinos G, Watson C. 1997. The rat brain in stereotaxic coordinates. Academic Press, New York, NY.

Pikkarainen M, Ronkko S, Savander V, Insausti R, Pitkanen A. 1999. Projections from the lateral, basal, and accessory basal nuclei of the amygdala to the hippocampal formation in rat. J Comp Neurol 403: $229-260$.

Ramirez DR, Bell GH, Lasseter HC, Xiaohu X, Traina SA, Fuchs RA. 2009. Dorsal hippocampal regulation of memory reconsolidation processes that facilitate drug context-induced cocaine-seeking behavior in rats. Eur I Neurosci 30: 901-912.

Rezayof A, Habibi P, Zarrindast MR. 2011. Involvement of dopaminergic and glutamatergic systems of the basolateral amygdala in amnesia produced by the stimulation of dorsal hippocampal cannabinoid receptors. Neuroscience 175: 118-126.

Richter-Levin G, Akirav I. 2001. Amygdala-hippocampus dynamic interaction in relation to memory. Mol Neurobiol 22: 11-20.

Roozendaal B, McGaugh JL. 1997. Basolateral amygdala lesions block the memory-enhancing effect of glucocorticoid administration in the dorsal hippocampus of rats. Eur J Neurosci 9: 76-83.

Sara SJ. 2000. Retrieval and reconsolidation: Toward a neurobiology of remembering. Learn Mem 7: 73-84.

Taylor JR, Olausson P, Quinn JJ, Torregrossa MM. 2009. Targeting extinction and reconsolidation mechanisms to combat the impact of drug cues on addiction. Neuropharmacology 56: 186-195.

Théberge FR, Milton AL, Belin D, Lee JL, Everitt BJ. 2010. The basolateral amygdala and nucleus accumbens core mediate dissociable aspects of drug memory reconsolidation. Learn Mem 17: 444-453.

Thomas MJ, Kalivas PW, Shaham Y. 2008. Neuroplasticity in the mesolimbic dopamine system and cocaine addiction. Br J Pharmacol 154: $327-342$.

Tran-Nguyen LTL, Fuchs RA, Coffey GP, Baker DA, O'Dell LE, Neisewander JL. 1998. Time-dependent changes in cocaine-seeking behavior and extracellular dopamine levels in the amygdala during cocaine withdrawal. Neuropsychopharmacology 19: 48-59.

Tronson NC, Taylor JR. 2007. Molecular mechanisms of memory reconsolidation. Nat Rev Neurosci 8: 262-275.

Valjent E, Corbille AG, Bertran-Gonzalez J, Herve D, Girault JA. 2006. Inhibition of ERK pathway or protein synthesis during reexposure to drugs of abuse erases previously learned place preference. Proc Natl Acad Sci 103: 2932-2937.

van Duuren E, van der Plasse G, van der Blom R, Joosten RN, Mulder AB, Pennartz CA, Feenstra MG. 2007. Pharmacological manipulation of neuronal ensemble activity by reverse microdialysis in freely moving rats: A comparative study of the effects of tetrodotoxin, lidocaine, and muscimol. J Pharmacol Exp Ther 323: 61-69.

Van Groen T, Wyss JM. 1990. Extrinsic projections from area CA1 of the rat hippocampus: Olfactory, cortical, subcortical, and bilateral hippocampal formation projections. J Comp Neurol 302: 515-528

Witter MP, Groenewegen HJ, Lopes da Silva FH, Lohman AH. 1989. Functional organization of the extrinsic and intrinsic circuitry of the parahippocampal region. Prog Neurobiol 33: 161-253.

Received May 9, 2011; accepted in revised form August 30, 2011. 


\section{Erratum}

Learning \& Memory 18: 693-702 (2011)

Interaction between the basolateral amygdala and dorsal hippocampus is critical for cocaine memory reconsolidation and subsequent drug context-induced cocaine-seeking behavior in rats

Audrey M. Wells, Heather C. Lasseter, Xiaohu Xie, Kate E. Cowhey, Andrew M. Reittinger, and Rita A. Fuchs

The authors mistakenly reported in several places in the above-mentioned article that the concentration of the baclofen/muscimol administered to rats was $1.0 / 0.01 \mathrm{mM}$. The correct dose is $1.0 / 0.1 \mathrm{mM}$. 


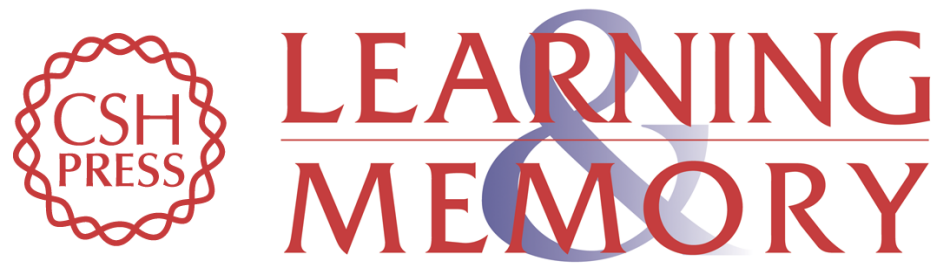

\section{Interaction between the basolateral amygdala and dorsal hippocampus is critical for cocaine memory reconsolidation and subsequent drug context-induced cocaine-seeking behavior in rats}

Audrey M. Wells, Heather C. Lasseter, Xiaohu Xie, et al.

Learn. Mem. 2011, 18:

Access the most recent version at doi:10.1101//m.2273111

Supplemental http://learnmem.cshlp.org/content/suppl/2011/10/12/18.11.693.DC1
Material

Related Content Erratum

Learn. Mem. April , 2013 20: 236

References This article cites 76 articles, 17 of which can be accessed free at: http://learnmem.cshlp.org/content/18/11/693.full.html\#ref-list-1

Articles cited in:

http://learnmem.cshlp.org/content/18/11/693.full.html\#related-urls

License

Email Alerting Receive free email alerts when new articles cite this article - sign up in the box at the Service top right corner of the article or click here. 